\title{
Accounting
}

\section{An empirical investigation of the strategic auditing: The case of the Algerian water enterprise of} El-Taref

\author{
Slimani Mounira ${ }^{\mathrm{a}}$, Haouli Mohamed ${ }^{\mathrm{a}^{*}}$, Dris Khaled ${ }^{\mathrm{a}}$, Omar Bagais ${ }^{\mathrm{b}}$ and Khaled Aljaaidi ${ }^{\mathrm{b}}$
}

${ }^{a}$ University Badji Moukhtar, Annaba, Algeria

${ }^{b}$ Prince Sattam bin Abdulaziz University, Saudi Arabia

\section{H R O N I C L E}

Article history:

Received: April 29, 2020

Received in revised format: July 302020

Accepted: August 10, 2020

Available online:

August 17, 2020

Keywords:

Strategic auditing

Diagnostic

Focused Analysis

Recommendations

Algerian Water Enterprise of $\mathrm{El}$ -

Taref

\section{A B S T R A C T}

The purpose of this study is to investigate the reality of strategic auditing in Algerian Water Enterprise of El-Taref. The study is theoretically developed based on three main dimensions, namely; diagnoses, focused analysis, and recommendations. The sample of this study consists of 47 employees in the Algerian Water Enterprise El-Taref. The results of the Factor Analysis, Mean and Coefficient covariance showed that there is an average level of the strategic auditing dimensions. The results of this study are important for policy makers at the country and the company levels in terms of the strategic auditing issues.

\section{Introduction}

Urgent matters and obstacles that were not taken into account are not uncommon to many strategic decision-makers. Dealing with these issues directly is influenced by multiple crises (Lai et al., 2020). Therefore, the strategic decision-makers have to take necessary measures to avoid them during strategic decision-making residency. The methods used when addressing the obstacles and crises may impact the process of strategic decision-making as well as implementation either positively or negatively. Consequently, coming up with an effective method to assist strategic decision-makers in subduing the challenges and crises that they face during the tasks involved in the formulation of the decisions is necessary. The essence of this tool is to prevent the strategic decision-maker from being preoccupied with looking for new methods of overcoming the challenges and, therefore, keep them focused on the main task assigned to them. The tool attains this by providing an oversight task that will help the strategic decision-maker to subdue the challenges and crises that they might face as well as offer the necessary recommendations to rectify the chosen options (Shawqi, 2020; Akbar \& Sajid, 2010). As a form of management audit, a strategic audit is more comprehensive and broader as it develops a comprehensive evaluation of the overall strategic milestone. Strategic audits describe the formulation of objectives, policies, and strategies as strategic decisions in addition to their implementation, assessment, and control through budgets, programs, and procedures in situations where the business's external environment creates opportunities for exploitation and threats, which should be avoided because they are harmful. Companies should have * Corresponding author.

E-mail address: mohamed.haouli@univ-annaba.dz (H. Mohamed) 
the necessary resources and capabilities to take advantage of opportunities and counter threats. Therefore, to ensure proper positioning to address the opportunities and threats, resource orientation reviews have to be conducted. Strategic auditing, which is an essential portion of business strategies, requires decision-makers to ensure or assure assessment and proper understanding of their resources (Al-Shaabani \& Al-Jumaili, 2012; Grundy, 2007; Phan et al., 2920). To the best of the researchers' knowledge, no study examining the strategic auditing in the Algerian Water Enterprise of El-Taref exists. Therefore, the focus of this study is to evaluate the attitudes of 47 employees of Algerian Water Enterprise of El-Taref regarding the current reality of the strategic auditing and whether it reflects the strategic auditing dimensions. In specific, this study aims at achieving the following research objectives: (1) To determine the existence of the strategic auditing dimensions from the perception of the employees of the Algerian Water Enterprise of El-Taref, (2) To identify the direction strategic auditing dimensions from the perception of the employees of the Algerian Water Enterprise of El-Taref, And (3) To investigate the most important strategic auditing dimensions from the perception of the employees of the Algerian Water Enterprise of El-Taref.

The remainder of the paper proceeds as follows: The next section briefly discusses the literature review. The third section describes the research methodology. The empirical results and discussions of the study are reported in the fourth section while in the final section, conclusion is drawn.

\section{Literature review}

Several scholars have defined strategic auditing as an inclusive, orderly, and intermittent evaluation of an organization and its management, including an inclusive assessment of the goals, policies, programs, strategies, and measures taken, which were devised to determine the weaknesses and strengths of the strategy or decision implementation to provide the necessary recommendations for improving the strategic performance of the organization in all areas (El-Sabagh \& Abou-Nebaa, 1990). Further, it is described as a focused assessment an organization's long-term decisions at the higher management level due to the changes in the internal and external environments for the organization's wholesome success and achievement of the long-term goals through analysis and testing of the strategic alternatives available and their consequences in addition to finding out the effects of disparities and addressing them promptly (Sekak, 2015). It is also described as a system that ensures all business units attain their objectives through measuring the actual performance in levels set for targeted performance and then comparing the actual performance to set criteria for identification of how well the targeted performances have been achieved (Al-Shaabani \& Al-Jumaili, 2012; Ul-Hameed et al., 2019).

Strategic auditing involves a checklist with questions that incorporate every stage in the process of strategic management, starting from the strategic analysis of the internal environment to the accomplishment of the process of implementation and strategic oversight. A strategic audit is a form of administrative audit that can be employed by the senior management of an organization or a skilled committee. Also, strategic auditing has the main goals, as outlined next (Djaradat, 2013): (1) To determine the degree of the relationship between the organization and the community where it operates depending on the organization's accomplishments and social practice and its response to the client's needs and wants, (2) To explain the degree to which different work activities contribute to the achievement of the mission and vision of the organization, (3) To identify how effective teamwork, organization, and integration are and the extent to which communication occurs in the different strategic units of the organization, (4) To identify and explain the organizational strengths and weaknesses through comparison with other organizations in the same industry. There are multiple aspects to the process of strategic auditing in the area of strategic management. These include the diagnostic aspect that involves reviews of critical documents and financial performance and outlining what is required for strategic implementation and the analytical aspect that involves hypothesis testing and coming up with conclusions, proposals, and recommendations. Of great importance is the strategic auditing of an organization's different operations (Djaradat, 2013). (5) To determine detectable changes that affect the organization's overall performance and, therefore, identify its threats and opportunities, (6) To increase the odds of attaining the formulated and adopted strategy because audits expose the weaknesses to be addressed and affirm the strengths, (7) To identify the effect of the changes implemented by the organization and the degree to which they contribute to improved organizational performance, (8) To determine and clarify the wants and needs of external stakeholders to meet them appropriately, (9) To define the needs and wants of consumers and aim at giving them high quality because audits forecast these needs and wants, (10) To provide a positive relationship between the various units in the organization as they work with each other in a cohesive and synchronized way to increase the chances of success (Djaradat, 2013; Al-Shaabani \& Al-Jumaili, 2012; Grundy, 2007; Tran et al., 2019).

\section{Research methodology}

\subsection{Questionnaire design}

This study is a quantitative method that was designed to explore the strategic auditing among the staff of the Algerian Water Enterprise of El-Taref. This study used the questionnaire as an appropriate data collection instrument for the purpose of answering the determined research questions: (1) what is the degree of existence of the strategic auditing dimensions from the 
perception of the employees of the Algerian Water Enterprise of El-Taref?, (2) what is the direction of the strategic auditing dimensions from the perception of the employees of the Algerian Water Enterprise of El-Taref?, and (3) what is the most important strategic auditing dimensions from the perception of the employees of the Algerian Water Enterprise of El-Taref?

The questionnaire consists of two different sections. The first section included subject information and the second section included demographic information and questions related to the strategic auditing degree among the employees at Algerian Water Enterprise of El-Taref. To test the face validity and content validity, three subject experts duly reviewed the questionnaire before distributing it out. The final questionnaire composed of 15 items that represent three constructs, namely; diagnosis, focused analysis and recommendations.

\subsection{Instrument of measurement}

The three strategic auditing constructs are measured using a five-point Likert Scale. The five-point Likert Scale is ranging from 1 (totally agree), indicating the highest level of agreement of the construct, to 5 (totally disagree), indicating to the lowest level of agreement of the construct. The strategic auditing dimensions examined in this study include: The dimensions of the strategic auditing are as follows: (1) Diagnosis: it includes gathering information to learn about the strategy and goals of the organization, as well as knowing the level of expected disease and the results that must be reached and knowing how to carry out the tasks and activities, that is, it is a comprehensive diagnosis of everything related to the management of the organization, (2) Focused Analysis: it includes modes of threats and opportunities for development, by analyzing specific issues, and defining internal relationships between components or components of the strategic system. The hypothesis test is followed by the formulation of conclusions regarding weaknesses in strategy formulation and implementation defects, and (3) Recommendations: this stage includes developing alternative solutions to problems, and testing them against the requirements of their strategic resources, and other applicable procedures. This is followed by the development of specific recommendations to present an integrated and measurable plan of action to improve strategic outcomes.

\subsection{Data collection and statistical analyses}

The population of interest in this study encompasses of all the employees working in the Algerian Water Enterprise of El-Taref. A total of 47 questionnaires were distributed out to all the target population. All the distributed questionnaires were retained back and were usable for analysis with a response rate of $100 \%$.

The descriptive and analytical approach that includes the use of the field method in data collection by the form as the main tool for the study, and its statistical analysis based on the method of global analysis, in addition to the desk survey, were used to take advantage of books and scientific periodicals to build the theoretical framework and bibliographic research by Computer on previous studies. It is worth clarifying that factor analysis is one of the statistical methods that are used in treating the results, as it is a statistical method that aggregates variables of one nature into a homogeneous structure internally linked with each other. An exploratory factor analysis was relied on in this study to discover the validity of the model that was developed to verify its global structure from the use of exploratory factor analysis as a first step. This kind of factor analysis can know the number of factors that represent a particular feature, and whether these factors are related to each other or are they independent not connected. In particular, the following statistical methods were used:

- Kurtosis and skewness coefficients: To ensure the normal distribution of data because it is a prerequisite for global analysis (the skewness coefficient is limited between $[1,-1]$ and the kurtosis coefficient is between $[3,-3]$ ).

- Coefficient of tolerance and Vif: to ensure the degree of independence between variables (the coefficient of Vif should not exceed 10, and the tolerance coefficient should not exceed 0.05 ).

- Arithmetic mean: To know the directions of the sample members on the questionnaire's questions.

- Standard deviation and coefficient of variation: to identify the strength of dispersion in the answers.

- Factorial analysis: through the following:

- Correlation Matrix: Transactions must be greater than 0.30 and not exceed 0.80 .

- Kaiser-Mayer-Olkin (KMO) test, and Bartlett's Test of Sphericity test: To ensure only the quality of the measurement is a Kaiser test, the indicators must not be less than 0.5 to judge the sampling level, and the Bartlett D test must be statistically significant. 
- The underlying roots of the correlation matrix and the sum of squares of saturation values before and after rotation: To explain the variance and the logic on which this method is based, the minimum variance that the factor interprets must be greater than the correct one, according to the Kaiser criterion.

- Cumulus of latent roots: It is a graph showing the factors more precisely. This method is based on latent roots.

- Matrix of components, factors or saturations before rotation: through which the paragraph saturation is presented to the factors (it should be from 0.30 and above).

- Matrix of factors after recycling: Where the reliance on the orthogonal method of varimax rotation was adopted, and on the basis of it, weak and high saturations arise in order to facilitate the interpretation of the factor.

\section{Empirical results and discussions}

Arithmetic mean, standard deviations and difference coefficients for sample responses are exhibited as shown in Table 1.

Table 1

Mean and coefficient of variance

\begin{tabular}{lccc}
\hline \multicolumn{1}{c}{ Dimensions } & Mean & Standard deviation & Coefficient of variance \\
\hline Diagnostic & 2.77 & 1.205 & 43.50 \\
Focused analyses & 2.80 & 1.149 & 41.03 \\
Recommendations & 2.57 & 1.341 & 52.17 \\
\hline
\end{tabular}

Table 1 shows that the approval levels for all dimensions are of a moderate degree, except after the recommendations are of a low degree, whereas the difference coefficients belong to the second domain $(30 \leq \mathrm{cd}<50 \%)$ and reflect dispersion considering that the answers and the views of the respondents are not close. After the analysis, it ranked first with an arithmetic mean of 2.80 , followed by second place after the diagnosis with an arithmetic mean of 2.77 , and after the recommendations, it ranked third and last with an arithmetic mean of 2.57 .

It is an important step and a first rule. One of the conditions for global analysis is to verify the moderation of the probability distribution, as this was achieved by relying on the torsional and flattening coefficients, and the results are shown as follows:

\section{Table 2}

Normality test

\begin{tabular}{lcc}
\hline \multicolumn{1}{c}{ Dimensions } & Kurtosis & Skewness \\
\hline Diagnostic & -0.134 & -0.351 \\
Focused analyses & -0.094 & -0.079 \\
Recommendations & 0.393 & 0.499 \\
\hline
\end{tabular}

Table 2 shows that the convolution coefficients are between -0.258 and 0.519 , and the Flatulence coefficients are confined between -0.718 and 1.771. This result indicates that the normal distribution is achieved because the convolution coefficients are confined to its range [1,-1], and the Flatulence coefficients are confined to Between the domain [3.-3]. Table 3 depicted the multicollinearity analysis using the Variance Inflation Factor VIF and Tolerance test for each variable.

Table 3

Tolerance and VIF tests

\begin{tabular}{lcc}
\hline \multicolumn{1}{c}{ Dimensions } & Tolerance & VIF \\
\hline Diagnostic & 0.359 & 2.788 \\
Focused analyses & 0.229 & 2.75 \\
Recommendations & 0.406 & 2.466 \\
\hline
\end{tabular}

Table 3 illustrates that inflation coefficient values for all dimensions do not exceed 10, and the allowed variance coefficients exceed 0.05 , and this indicates that there is no high self-correlation between the variables. 
Despite the significance of the correlation matrix, this does not mean that all correlations are appropriate but should be supported by other tests, ensuring the quality of the measurement through the Kaiser-Mayer-Olkin (KMO) test, and Bartlett's Test of Sphericity, and the results are shown as follows:

\section{Table 4}

$\underline{\mathrm{KMO} \text { and Bartlett's Test }}$

Kaiser-Meyer-Olkin Measure of Sampling Adequacy.

Bartlett's Test of Sphericity

\begin{tabular}{ll} 
& .759 \\
Approx. Chi-Square & 633.883 \\
Df & 190 \\
Sig. & .000 \\
\hline
\end{tabular}

Table 4 shows the Kaiser-Mayer-Olkin (KMO) test equal to 0.759 and it ranges from 0.70 to 0.80 according to the Kaiser motors and is an acceptable result, and this result indicates that the correlations are at an acceptable level and that the sample size is appropriate for performing the factor analysis. The Bartlett's Test of Sphericity has a statistically significant value of less than 0.05 , and this indicates that the relationship index between the variables is good. Table 5 illustrates that the values of the latent roots of the extracted factors by which the amount of variance in the variable to which the change in a given factor is inferred, has been summarized in four latent roots greater than the correct one, using the basic components method with orthogonal rotation according to the latent root value on Straight. As it is clear from the table that the safe root of the first factor is 11.054, and this factor contributed to the interpretation of $55.26 \%$ of the variations structure of the strategic audit variables. It is also noticed that the rotation distributes the proportions of the variance distributed between the factors in a relatively balanced way and does not make it center in the first factor as shown in the last three columns in the table.

\section{Table 5}

The underlying roots of the correlation matrix and the sum of the saturation value boxes before and after rotation

\begin{tabular}{|c|c|c|c|c|c|c|c|c|c|}
\hline \multirow[b]{2}{*}{ Component } & \multicolumn{3}{|c|}{ Initial Eigenvalues } & \multicolumn{3}{|c|}{ Extraction Sums of Squared Loadings } & \multicolumn{3}{|c|}{ Rotation Sums of Squared Loadings } \\
\hline & Total & $\%$ of Variance & Cumulative \% & Total & $\%$ of Variance & Cumulative \% & Total & $\%$ of Variance & Cumulative $\%$ \\
\hline 1 & 11.054 & 55.268 & 55.268 & 11.054 & 55.268 & 55.268 & 5.042 & 25.211 & 25.211 \\
\hline 2 & 1.861 & 9.307 & 64.575 & 1.861 & 9.307 & 64.575 & 3.745 & 18.726 & 43.937 \\
\hline 3 & 1.057 & 5.286 & 69.861 & 1.057 & 5.286 & 69.861 & 3.530 & 17.650 & 61.587 \\
\hline 4 & 1.011 & 5.057 & 74.917 & 1.011 & 5.057 & 74.917 & 2.666 & 13.331 & 74.917 \\
\hline 5 & .878 & 4.391 & 79.309 & & & & & & \\
\hline 6 & .824 & 4.121 & 83.430 & & & & & & \\
\hline 7 & .630 & 3.148 & 86.578 & & & & & & \\
\hline 8 & .569 & 2.844 & 89.422 & & & & & & \\
\hline 9 & .439 & 2.195 & 91.617 & & & & & & \\
\hline 10 & .388 & 1.938 & 93.555 & & & & & & \\
\hline 11 & .323 & 1.615 & 95.170 & & & & & & \\
\hline 12 & .234 & 1.170 & 96.340 & & & & & & \\
\hline 13 & .206 & 1.030 & 97.369 & & & & & & \\
\hline 14 & .154 & .770 & 98.140 & & & & & & \\
\hline 15 & .114 & .572 & 98.712 & & & & & & \\
\hline 16 & .088 & .442 & 99.154 & & & & & & \\
\hline 17 & .077 & .383 & 99.537 & & & & & & \\
\hline 18 & .045 & .223 & 99.760 & & & & & & \\
\hline 19 & .032 & .161 & 99.921 & & & & & & \\
\hline 20 & .016 & .079 & 100.000 & & & & & & \\
\hline
\end{tabular}

Extraction Method: Principal Component Analysis.

The cumulus of latent roots is illustrated in the following Fig. 1.

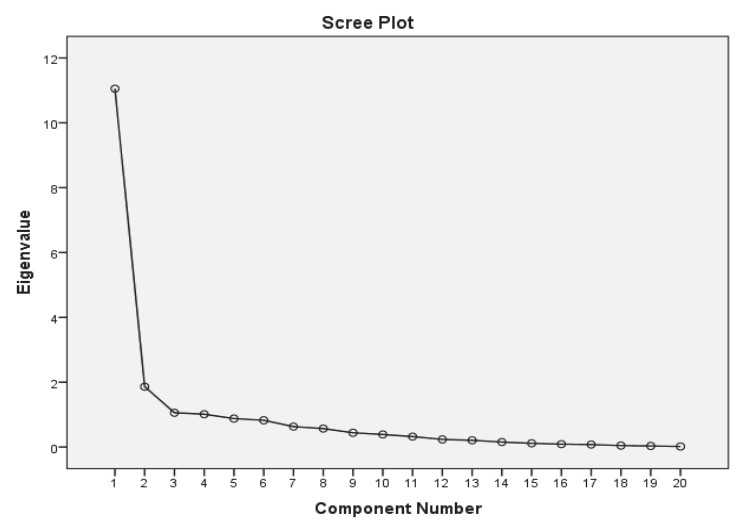

Fig. 1. Aggregate of latent roots corresponding to various factors 
Fig. 1 illustrates the so-called scree plot curve method, i.e. the values of the underlying roots of each factor on the vertical axis and the component number on the horizontal axis. The slope method is accurate, that is, the number of extracted factors is stable. The graph is another criterion by which the factors whose root potential exceeds the correct one can be preserved to determine the factors in the global analysis and keep only those that are in the steep slope. Accordingly, the figure shows the pattern of the underlying roots of each extracted factor, and it becomes apparent from the figure that the region in which the curve that connects the points takes a roughly horizontal position that begins to appear between the first and fourth factors.

Table 6

Component matrix

\begin{tabular}{|c|c|c|c|c|}
\hline & \multicolumn{4}{|c|}{ Component } \\
\hline & 1 & 2 & 3 & 4 \\
\hline $\mathrm{X} 18$ & .886 & & & \\
\hline X5 & .847 & & & \\
\hline $\mathrm{X} 13$ & .845 & -.336 & & \\
\hline X16 & .845 & & & \\
\hline X7 & .837 & & & \\
\hline X3 & .829 & & & \\
\hline $\mathrm{X} 4$ & .824 & & & \\
\hline X14 & .802 & -.383 & & \\
\hline $\mathrm{X} 15$ & .786 & -.389 & & \\
\hline X17 & .775 & & & .429 \\
\hline $\mathrm{X} 2$ & .735 & & & -.369 \\
\hline X6 & .719 & & & \\
\hline X9 & .715 & & & .325 \\
\hline $\mathrm{X} 12$ & .647 & & .482 & \\
\hline X8 & .637 & .590 & & \\
\hline X11 & .637 & & & -.324 \\
\hline X19 & .635 & & -.505 & \\
\hline $\mathrm{X} 10$ & .588 & .536 & & \\
\hline $\mathrm{X} 1$ & .586 & .500 & & \\
\hline $\mathrm{X} 20$ & .550 & .307 & .528 & \\
\hline
\end{tabular}

Extraction Method: Principal Component Analysis.

a. 4 components extracted.

Table 6 shows that all of the paragraphs are satisfied with the first factor, and saturation on the second factor is 07 paragraphs of 20 paragraphs, while the third factor is satiated with 03 paragraphs, and the fourth factor is satiated with 04 paragraphs, and it is a common saturation because the paragraphs that satiated the second, third and fourth factors are the same as saturating the factor the first.

Table 7

Rotated component matrix

\begin{tabular}{|c|c|c|c|c|}
\hline & \multicolumn{4}{|c|}{ Component } \\
\hline & 1 & 2 & 3 & 4 \\
\hline X5 & .755 & .366 & .337 & \\
\hline $\mathrm{X} 4$ & .731 & .315 & .356 & \\
\hline $\mathrm{X} 11$ & .715 & & & \\
\hline $\mathrm{X} 2$ & .692 & .411 & & \\
\hline $\mathrm{X} 13$ & .659 & & .500 & .399 \\
\hline $\mathrm{X} 12$ & .658 & & & .532 \\
\hline X16 & .630 & & .453 & \\
\hline X18 & .510 & .316 & .508 & .436 \\
\hline $\mathrm{X} 8$ & & .843 & & \\
\hline $\mathrm{X} 10$ & & .817 & & \\
\hline $\mathrm{X} 1$ & & .687 & & \\
\hline X7 & .511 & .641 & .340 & \\
\hline X19 & & & .826 & \\
\hline X14 & .505 & & .740 & \\
\hline X15 & .583 & & .636 & \\
\hline X9 & & .498 & .525 & .401 \\
\hline $\mathrm{X} 20$ & & & & .790 \\
\hline X17 & & .427 & .491 & .644 \\
\hline X3 & .461 & .426 & .324 & .466 \\
\hline X6 & .383 & .341 & & .446 \\
\hline
\end{tabular}

Extraction Method: Principal Component Analysis.

Rotation Method: Varimax with Kaiser Normalization. ${ }^{\mathrm{a}}$

a. Rotation converged in 9 iterations. 
As shown by Table 7 that as comparing this matrix before rotation and after rotation, it is noted that the rotation redistributes the contrast explained by each factor, as the moderate high saturations (G11, G08, G10, G01, G19, G20), while the rest of the paragraphs are moderate. Intersectional, from which the saturation is satiated indicating two factors, i.e. two saturation intersections (p. 02, p. 12, p. 16, p. 14, p. 15), of which there are three intersections (p. 05, p. 04, p. 13, p. 07, p. 09, p. 17)., P06), and the remainder have quadruple cross-reliefs (p03 and 18). Table 10 shows the saturation values after rotation as follows:

\section{Table 10}

Saturation values of factors with variables after rotation

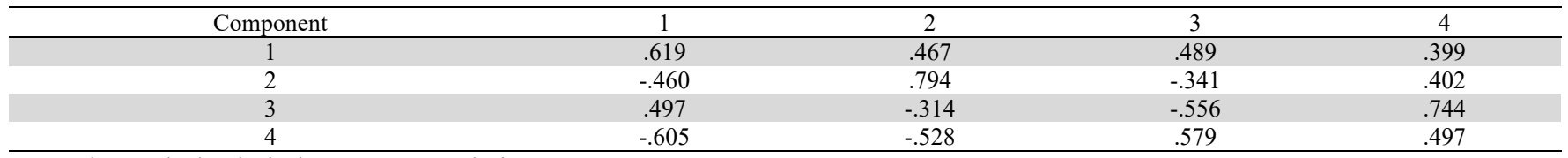

Extraction Method: Principal Component Analysis.

Rotation Method: Varimax with Kaiser Normalization.

Table 10 shows the amount and strength of the relationship between the factors, i.e. the extent of a correlation between the factors, as the table shows that the value of the transactions is between 0.314 and 0.794 , and this indicates that the factors are moderately correlated, because the transactions exceed 0.30 and not exceed 0.80 .

\section{Conclusion}

The study has concluded that strategic auditing is a tool if it is used correctly and it would assist companies to have an effective strategy. As broader type of administrative audit, it is what creates an assessment of the overall strategic situation as it does not only describe how to formulate goals, strategies and policies as strategic decisions, but it goes beyond how to implement them Straightening and controlling it with scales, budgets, and procedures. Further, this study finds that strategic auditing contributes in developing an integrated system that increases the effectiveness of organizations by using the strategic audit method. This study is subject to a limit which is the inability to examine the strategic and social auditing in business organizations in practice, despite their importance. Therefore, this study suggests for future line of research to empirically examine the strategic and social audits.

\section{References}

Akbar, M. \& Sajid, A. (2012). Strategic audit of Emirates Global Islamic Bank Limited, Shadman, Pakistan. New York Science Journal 3(3).

Al-Shaabani, S. \& Al-Jumaili, W. (2012). Application features of the strategic audit in Iraq: Study of a sample of industrial companies in the Province of Nineveh. Journal of Al-Anbaar University for Administrative and Economic Studies, 4(9).

Djaradat, N. (2013). Management strategic-A modern integrative perspective. Ithra, Djordani.

El-Sabagh, Z. \& Abou-Nebaa, A. (1990). Strategic auditing of human power organizational diagram. King Saud University Review, 2.

Grundy, T. (2007). Strategic audit: why it's vital to give your strategy a health check. Gale, Cengage Learning, Chartered Institute of Management Accountants (CIMA).

Lai, T., Tran, M., Hoang, V., \& Nguyen, T. (2020). Determinants influencing audit delay: The case of Vietnam. Accounting, $6(5), 851-858$.

Phan, T., Lai, L., Le, T., \& Tran, D. (2020). The impact of audit quality on performance of enterprises listed on Hanoi Stock Exchange. Management Science Letters, 10(1), 217-224.

Sekak, M. (2015): The role of strategic auditing in management strategic of organizations- Empirical study for some enterprises in Setif province, economic science and management science review 15.

Shawqi, A. (2020) Strategic audit in business organizations.

Tran, M., Pham, T., Phan, T., Hoang, T., Do, D., \& Dinh, T. (2019). Factors influencing independent audit fees: Multi-group analysis PLS-SEM and moderate model. Management Science Letters, 9(10), 1599-1608.

Ul-Hameed, W., Mohammad, H., Shahar, H., Aljumah, A., \& Azizan, S. (2019). The effect of integration between audit and leadership on supply chain performance: Evidence from UK based supply chain companies. Uncertain Supply Chain Management, 7(2), 311-328. 
(C) 2020 by the authors; licensee Growing Science, Canada. This is an open access article distributed under the terms and conditions of the Creative Commons Attribution (CC-BY) license (http://creativecommons.org/licenses/by/4.0/). 